\title{
Genetic Evidence for a Common Pathway Mediating Oxidative Stress, Inflammatory Gene Induction, and Aortic Fatty Streak Formation in Mice
}

\author{
Feng Liao, * Ali Andalibi, * Jian-Hua Qiao, “ Hooman Allayee, * Alan M. Fogelman, * and Aldons J. Lusis ** \\ *Department of Medicine, Division of Cardiology, University of California, Los Angeles, School of Medicine; and ${ }^{\ddagger}$ Department of \\ Microbiology and Molecular Genetics, and Molecular Biology Institute, University of California, Los Angeles, California 90024
}

\begin{abstract}
In a previous survey of inbred mouse strains on an atherogenic diet, we observed that the susceptibility to aortic atherosclerotic lesion formation was associated with the accumulation of lipid peroxidation products, induction of inflammatory genes, and the activation of NF-kB-like transcription factors (Liao, F., A. Andalibi, F. C. deBeer, A. M. Fogelman, and A. J. Lusis. 1993. J. Clin. Invest. 91:25722579). We hypothesized that the inflammation-related processes were stimulated by oxidized lipids, since injection of minimally oxidized LDL (MM-LDL) activated the same set of genes. We now report that the induction of inflammatory genes and activation of NF-kB-like transcription factors cosegregate with aortic atherosclerotic lesion formation in BXH recombinant inbred strains derived from parental C57BL/6J (susceptible) and $\mathrm{C} 3 \mathrm{H} / \mathrm{HeJ}$ (resistant) mice. In addition, the accumulation of hepatic conjugated dienes exhibited a significant correlation with inflammatory gene activation. These results provide strong evidence for the role of inflammatory mediators inducible by oxidative stress in atherogenesis. They also suggest that a major gene contributing to aortic lesion development in this mouse model, designated Ath-1, may control either the accumulation of lipid peroxides in tissues or the cellular responses to such lipid peroxides. (J. Clin. Invest. 1994. 94:877-884.) Key words: inflammatory serum amyloid $A \cdot$ heme oxygenase $\cdot$ lipid peroxides - NF-kB-like transcription factors - atherosclerosis
\end{abstract}

\section{Introduction}

A large body of evidence now implicates lipoprotein oxidation in the early stages of atherosclerosis (1-3). In particular, oxidized forms of LDL occur in atherosclerotic lesions (4-7), and lipophilic antioxidants have been shown to reduce lesion development in animal models (8-11). In vitro studies have revealed that oxidized LDL (minimally modified LDL [MM-

Address correspondence to Aldons J. Lusis, Department of Medicine, UCLA School of Medicine, Los Angeles, CA 90024-1679. 1994.

Received for publication 3 March 1994 and in revised form 6 May

J. Clin. Invest.

(C) The American Society for Clinical Investigation, Inc.

0021-9738/94/08/0877/08 \$2.00

Volume 94, August 1994, 877-884
LDL] $)^{1}$ are capable of inducing factors likely to mediate arterial monocyte recruitment as well as promoting monocytes to form foam cells (12-16). Several of the factors shown to be induced by MM-LDL, including monocyte chemotactic protein-1 (MCP-1) and macrophage-colony stimulating factor (M-CSF), have subsequently been shown to be present in atherosclerotic lesions (17-19).

We have attempted to examine aspects of lipoprotein oxidation and inflammatory gene activation in vivo using a mouse animal model. We initially demonstrated that injection of MMLDL into mice stimulated expression of inflammatory mediators such as M-CSF in the circulation and JE (the mouse homolog of $\mathrm{MCP}-1$ ) in a variety of tissues, including liver (20). In contrast, injection of native LDL had no effect. We subsequently examined inflammatory gene expression in strains of mice either susceptible or resistant to the development of atherogenic lesions in the aorta after feeding of a high fat, high cholesterol "'atherogenic' diet. Striking differences were observed between the strains, and the degree of inflammatory gene expression was associated with genetic difference in susceptibility to atherogenesis (21). The highly susceptible strain C57BL/6J exhibited dramatic induction of M-CSF in the circulation and induction of JE, inflammatory serum amyloid A (SAA) and heme oxygenase in liver. In contrast, the resistant strain $\mathrm{C} 3 \mathrm{H} / \mathrm{HeJ}$ showed minimal induction of these genes in response to the atherogenic diet. In addition, strain C57BL/6J mice exhibited significantly greater accumulation of hepatic conjugated dienes, an indicator of lipid peroxidation products, than strain $\mathrm{C} 3 \mathrm{H} / \mathrm{HeJ}$ mice.

Both the liver and the arterial wall are the sites for the accumulation of lipids and lipid peroxides in animals fed the atherogenic diet. It is noteworthy that the pattern of gene activation after feeding of the atherogenic diet was the same as that observed after injection of MM-LDL (21). Several lines of evidence suggested that the inflammatory gene activation was mediated by oxidative stress. First, oxidized lipids accumulated in response to the atherogenic diet. Second, genes responsive to oxidative stress, including heme oxygenase and glutathione$S$-transferase mu, were induced. And third, inflammatory gene induction was paralleled by activation of an NF-kB-like transcription factor (21). NF-kB is known to be activated by oxidative stress (22).

We now report genetic studies to examine the possible relationships among NF-kB-like transcription factor activation,

1. Abbreviations used in this paper: MCP-1, monocyte chemotactic protein-1; M-CSF, macrophage-colony stimulating factor; MM-LDL, minimally modified LDL; RI, recombinant inbred; SAA, serum amyloid A. 
lipid peroxide accumulation, inflammatory gene induction, and aortic fatty streak development. We have previously provided evidence that a single major gene, designated Ath-1, contributes to the difference in development of aortic lesions between strain $\mathrm{C} 57 \mathrm{BL} / 6 \mathrm{~J}$ and $\mathrm{C} 3 \mathrm{H} / \mathrm{HeJ}$ mice (23). Because of the large nongenetic variance of aortic lesion development, recombinant inbred (RI) strains of mice provided a useful means of examining the inheritance of susceptibility to atherogenesis (24-26). RI strains are constructed by crossing two parental strains (C57BL/ $6 \mathrm{~J}$ and $\mathrm{C} 3 \mathrm{H} / \mathrm{HeJ}$ ) to produce $\mathrm{F} 1$ progeny, which are subsequently mated to give rise to $\mathrm{F} 2$ progeny containing different combinations of the parental genomes. The F2 animals are then brother-sister mated for many generations to yield new sets of inbred strains. The resulting RI strains contain unique combinations of the parental genomes and are useful for testing relationships between complex genetic traits. Thus, if two traits are causally linked or determined by common genetic factors, they should cosegregate among the members of RI strains sharing the same determining gene $(\mathrm{s})$. In the experiments reported here we utilized RI strains derived from $\mathrm{C} 57 \mathrm{BL} / 6 \mathrm{~J}$ and $\mathrm{C} 3 \mathrm{H} / \mathrm{HeJ}$ mice (designated $\mathrm{BXH}$ ). Our results indicate that NF-kB-like transcription factor activation, hepatic inflammatory gene induction, and aortic fatty streak development all cosegregate. Moreover, a significant correlation was observed between the accumulation of hepatic conjugated dienes and inflammatory gene activation. Thus, our results provide strong in vivo evidence for functional relationships among these processes.

\section{Methods}

Mice and diets. Parental C57BL/6J and $\mathrm{C} 3 \mathrm{H} / \mathrm{HeJ}$ mice as well as the BXH RI strains were purchased from The Jackson Laboratory (Bar Harbor, ME). All animals were female, 4-6 months of age, at the time of the experiment. The control (chow) diet was Purina Chow (RalstonPurina Co., St. Louis, MO) containing $4 \%$ fat. The atherogenic diet was obtained from Teklad, Madison, WI (TD 90221) and contained 15.75\% fat, $1.25 \%$ cholesterol, and $0.5 \%$ sodium cholate (24).

RNA analysis. Tissues were collected, frozen in liquid nitrogen, and stored at $-70^{\circ} \mathrm{C}$. Total RNA was extracted from the frozen tissues using the guanidinium thiocyanate-phenol-chloroform method (27). Total RNA $(0.25-1.0 \mathrm{mg})$ was applied to nylon filters using the ELIFA dot blot apparatus (Pierce, Rockford, IL). RNA samples were diluted with equal volumes of SSC/formaldehyde ( $60 \% 20 \times \mathrm{SSC}$ and $40 \%$ formaldehyde), incubated at $65^{\circ} \mathrm{C}$, and cooled to room temperature before loading. After cross-linking with ultraviolet light, the filters were prehybridized in $7 \%$ SDS, $0.5 \mathrm{M}$ sodium phosphate, $1 \mathrm{mM}$ EDTA, $1 \%$ BSA $\mathrm{pH}$ 7.2. Hybridizations were performed in the same buffer overnight at $65^{\circ} \mathrm{C}$ with $18 \mathrm{~S}$ rRNA, $\mathrm{SAA}_{3}$, and heme oxygenase probes prepared by random labeling using Pharmacia Oligolabeling Kit (Parmacia, Piscataway, NJ). The blots were then washed in $0.1 \times \mathrm{SSC}, 0.1 \%$ SDS at $65^{\circ} \mathrm{C}$. The autoradiographs were quantitated by densitometric scanning. The levels of inflammatory SAA and heme oxygenase were normalized to those of $18 \mathrm{~S}$ rRNA. A number of samples from each strain were also analyzed by northern blotting, and the results were consistent with those obtained by dot blot assays. The $18 \mathrm{~S}$ rRNA (Rn18S) cDNA was purchased from American Type Culture Collection (Rockville, MD) (28). The murine heme oxygenase cDNA was kindly provided by Dr. S. Sakiyama (Chiba Cancer Center Research Institute, Japan) (29). The $\mathrm{SAA}_{3}$ cDNA (clone pRS48) $(30,31)$ was kindly provided by Dr. Ben Taylor (The Jackson Laboratory).

Nuclear extracts and mobility shift assays. Liver nuclear extracts were prepared according to previously published protocols with minor modifications $(32,33)$. Briefly, approximately 0.4 grams of liver tissue was minced in cold PBS and the minced chunks were disrupted in buffer A with $0.1 \%$ NP-40 using a Dounce homogenizer with a type B pestle.
The crude nuclear pellets were then resuspended in buffer $\mathrm{C}$ and then diluted with buffer D. Nuclear extracts were also prepared from cultured HeLa cells as previously described (33). Mobility shift assays were carried out according to a standard protocol using the Gibco/BRL NF$\mathrm{kB}$ and SP-1 binding protein detection systems (GIBCO BRL, Gaithersburg, MD). Since several transcription factors have been identified in the NF-kB family (34), the assays detect the activation of the sum of these transcription factors that recognize the consensus binding sequence. The autoradiographs were quantitated by densitometric scanning. Densitometric values for NF-kB-like bands of the same nuclear extracts prepared from HeLa cells treated with LPS served as the standard to account for the variation among different autoradiographs. The values obtained from different nuclear extracts were then further normalized to the internal standard SP-1, a constitutive transcription factor, to account for the variation of the nuclear extracts for different samples used in the assays.

Aortic lesion scoring. After killing the upper portion of the heart and proximal aorta were embedded in OCT compound and frozen on dry ice. Serial $10-\mu \mathrm{m}$-thick cryosections of aorta, beginning at the aortic root, were collected for a distance of $\sim 400 \mu \mathrm{m}(35,36)$. These sections were stained with oil red $\mathrm{O}$ and hematoxylin. The lipid-containing area on each section was determined by using a microscope eyepiece grid. The lesion scores are the average values of lipid staining areas of aortic wall per section.

Lipid extraction and measurement of conjugated dienes. Total lipids were extracted from livers of mice and conjugated dienes were measured using the second derivative ultraviolet absorption spectra of the lipids in hexane as previously described (21) using soybean lipoxygenase oxidized linoleic acid as a standard.

Statistical analysis. Correlations and levels of significance were calculated using the StatView (Abacus Concepts, Inc., Berkeley, CA). The correlations presented are for log-transformed data, but similar correlations were observed with the raw data.

\section{Results}

Cosegregation of induction of inflammatory genes. We previously observed that inbred strains $\mathrm{C} 3 \mathrm{H} / \mathrm{HeJ}$ and $\mathrm{C} 57 \mathrm{BL} / 6 \mathrm{~J}$ differed in the induction of a variety of inflammatory genes in response to the consumption of a high fat, high cholesterol, "'atherogenic', diet. Whereas strain C57BL/6J mice exhibited substantial induction of plasma M-CSF activity, plasma inflammatory SAA levels, hepatic inflammatory SAA mRNA levels, hepatic JE mRNA levels, hepatic heme oxygenase mRNA levels, and hepatic glutathione- $S$-transferase mRNA levels after 5-15 wk of feeding of the atherogenic diet, strain $\mathrm{C} 3 \mathrm{H} / \mathrm{HeJ}$ mice exhibited minimal or no induction of these proteins or transcripts. To test whether a common genetic factor (or set of genetic factors) determined the response of the genes to the diet, gene expression was studied in a set of ten RI strains (designated $\mathrm{BXH}$ ) derived from these two parental strains. If the same genetic factors, differing between the parental strains, are responsible for the induction of these genes, a concordant distribution of the expression of different genes should be observed among the RI strains. On the other hand, if the various genes are regulated independently, that is, by separate genetic factors, a discordant distribution would be observed due to independent segregation. Expression of hepatic mRNA levels of heme oxygenase and inflammatory SAA were chosen for this study. Both genes are highly responsive to the diet in C57BL/ $6 \mathrm{~J}$ but not $\mathrm{C} 3 \mathrm{H} / \mathrm{HeJ}$ mice (Table I).

Consumption of the atherogenic diet for 5 or $15 \mathrm{wk}$ resulted in the induction hepatic inflammatory SAA and heme oxygenase mRNA in a strain specific pattern (Table I, Fig. I). In general, those strains having higher levels of hepatic inflammatory SAA 
Table I. Phenotypes and Genotypes of Parental (C57BL/6J and C3H/HeJ) and of BXH RI Strains

\begin{tabular}{|c|c|c|c|c|c|c|c|}
\hline Strains & Lesion scores* & SAA units ${ }^{t}$ & HO units ${ }^{\ddagger}$ & apo A-IV units ${ }^{\ddagger}$ & NF-kB-like & Conjugated dienes" & Lps allele' \\
\hline C57BL/6J & $13,749 \pm 365$ & $15.7 \pm 1.6$ & $3.2 \pm 0.4$ & ND & $840 \pm 230$ & $1250 \pm 470$ & B \\
\hline $\mathrm{C} 3 \mathrm{H} / \mathrm{HeJ}$ & $673 \pm 41$ & $3.4 \pm 0.8$ & $1.5 \pm 0.2$ & ND & $20 \pm 2$ & $564 \pm 272$ & $\mathbf{H}$ \\
\hline BXH-3 & $2,496 \pm 498$ & $6.0 \pm 1.4$ & $2.0 \pm 0.3$ & $2.7 \pm 0.3$ & $126 \pm 45$ & $1148 \pm 241$ & $\mathbf{H}$ \\
\hline BXH-4 & $473 \pm 157$ & $5.3 \pm 0.9$ & $0.9 \pm 0.2$ & $3.8 \pm 0.5$ & $47 \pm 20$ & $1166 \pm 179$ & $\mathbf{H}$ \\
\hline BXH-6 & $563 \pm 221$ & $5.4 \pm 1.1$ & $3.0 \pm 0.7$ & $7.8 \pm 2.7$ & $23 \pm 4$ & $1075 \pm 184$ & $\mathbf{H}$ \\
\hline BXH-7 & $665 \pm 680$ & $3.0 \pm 0.4$ & $1.5 \pm 0.3$ & $5.0 \pm 0.5$ & $232 \pm 138$ & $829 \pm 228$ & $\mathbf{H}$ \\
\hline BXH-8 & $24,365 \pm 11,964$ & $8.5 \pm 2.2$ & $5.3 \pm 1.4$ & $7.0 \pm 1.5$ & $786 \pm 132$ & $1431 \pm 281$ & $\mathbf{H}$ \\
\hline ВXH-9 & $250 \pm 120$ & $1.9 \pm 0.4$ & $0.4 \pm 0.1$ & $5.8 \pm 1.0$ & $20 \pm 7$ & $682 \pm 775$ & $\mathbf{H}$ \\
\hline BXH-10 & $1,831 \pm 1,589$ & $3.8 \pm 1.4$ & $2.2 \pm 0.4$ & $4.2 \pm 0.6$ & $59 \pm 46$ & $680 \pm 328$ & B \\
\hline BXH-11 & $7,274 \pm 1,085$ & $12.0 \pm 1.9$ & $5.9 \pm 0.7$ & $3.9 \pm 0.6$ & $1425 \pm 45$ & $1954 \pm 280$ & B \\
\hline BXH-14 & $3,406 \pm 1,743$ & $5.5 \pm 1.8$ & $1.1 \pm 0.2$ & $4.0 \pm 0.5$ & $76 \pm 21$ & $560 \pm 292$ & B \\
\hline ВXH-19 & $13,080 \pm 3,479$ & $7.4 \pm 2.6$ & $1.4 \pm 0.2$ & $3.9 \pm 0.6$ & 286 & $654 \pm 215$ & B \\
\hline
\end{tabular}

The values shown are mean \pm SEM. 3-9 animals were included in each group and fed the atherogenic diet for 15 wk (except for only one animal of BXH-19 used for mobility shift assay). ${ }^{*}$ Lesion scores $\left(\mu \mathrm{m}^{2} / \mathrm{section}\right) . \quad{ }^{\ddagger}$ Densitometric units of particular mRNAs normalized to those of $18 \mathrm{~S}$ rRNA mRNA. 'Densitometric units of shifted radioactive-labeled oligonucleotide bands on mobility shift assays. "Conjugated dienes in the liver tissue ( $\mu \mathrm{mol} / \mathrm{g}$ wet weight). ' $\mathrm{B}$ : Lps gene inherited from C57BL/6; $\mathrm{H}:$ Lps gene inherited from C3H/HeJ. $N D$, not determined.

mRNA levels after 5 wk on the atherogenic diet also had higher levels after $15 \mathrm{wk}$ on the diet $(r=0.61, P=0.03)$. The same trend was observed for hepatic heme oxygenase mRNA levels ( $r=0.73, P=0.02$ ) (data not shown).

As shown in Table I, the patterns of inheritance of both inflammatory SAA and heme oxygenase mRNA levels were complex (non-Mendelian), suggesting the existence of multiple genetic factors, or of a single major gene with modifying factors, contributing to the induction by the atherogenic diet (see Discussion). That is, the values for the RI strains did not all resemble either one parent or the other, as expected for a single Mendelian factor. Clearly, however, induction of heme oxygenase and inflammatory SAA was highly concordant among the various RI strains (Fig. 2), whether analyzed using the average values for each strain $(r=0.74, P<0.0001)$ or the individual values $(r=0.61, P<0.0001)$.

As a control, we examined the inheritance of apolipoprotein A-IV (apo A-IV) expression. Like inflammatory SAA and heme

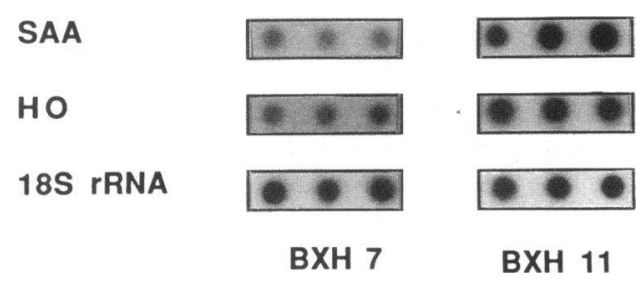

Figure 1. Dot blot assays for inflammatory SAA $(S A A)$, heme oxygenase $(H O)$, and $18 \mathrm{~S}$ rRNA. Total RNA was extracted from the liver tissues of mice on the atherogenic diet for $15 \mathrm{wk}$. The same amount of RNA from each mouse was applied to nylon films followed by hybridization with different probes. Strain specific patterns were observed in the BXH RI strains. The representative results for BXH 7 and BXH 11 are shown. Three animals were included for each strain. To quantitate the levels of inflammatory SAA and heme oxygenase, the ratio of the densitometric scan units of each of them with those of 18S rRNA were used. A number of samples from each strain were also analyzed by northern blotting, and the results were consistent with those obtained by dot blot assays. oxygenase, hepatic apo A-IV mRNA expression is highly responsive to the atherogenic diet and the response differed among inbred strains (37). However, neither inflammatory SAA nor heme oxygenase mRNA levels exhibited significant cosegregation with hepatic apolipoprotein A-IV mRNA levels (Fig. 3). Thus, the genetic factors mediating apo A-IV expression are distinct from those mediating inflammatory SAA and heme oxygenase expression.

Cosegregation of activation of $N F-k B$-like transcription factors with induction of inflammatory and oxidative stress responsive genes. We previously reported that strain $\mathrm{C} 57 \mathrm{BL} / 6 \mathrm{~J}$ mice exhibited dramatic activation of hepatic NF-kB, or closely related transcription factors, when maintained on the atherogenic diet, whereas strain $\mathrm{C} 3 \mathrm{H} / \mathrm{HeJ}$ exhibited marginally detectable levels of activated NF-kB-like factors on either the chow or the atherogenic diet (21). Since NF-kB binding sites are present in the promoters for at least some of the genes induced by MM-LDL injection or the atherogenic diet, including JE (38), M-CSF (39), inflammatory SAA (40), and tissue factor (41), our results suggest that activation of members of the NF$\mathrm{kB}$ family could mediate, in part, the induction of these genes. To further test this possibility, the levels of activated NF-kBlike factors in hepatic nuclear extracts were determined among the parental and BXH RI strains using the mobility shift assays (Table I, Fig. 4). The levels of activated NF-kB-like factors were concordant, among BXH RI strains and the parental strains, with the levels of heme oxygenase mRNA $(r=0.68$, $P=0.01)$, and inflammatory SAA mRNA $(r=0.77, P$ $=0.003$ ) in mice maintained on the atherogenic diet. NF-kBlike activity showed no significant correlation with the levels of hepatic apo A-IV mRNA ( $r=-0.17, P=0.63$ ) (Fig. 5).

Cosegregation of lipid peroxide accumulation and inflammatory gene induction. We previously observed that the accumulation of hepatic lipid peroxidation products, as estimated by the levels of conjugated dienes, was significantly greater in strain C57BL/6J mice than in strain $\mathrm{C} 3 \mathrm{H} / \mathrm{HeJ}$ mice fed the atherogenic diet. Total lipid levels, however, did not differ significantly between the strains on either chow or atherogenic diets (21). In this study, we observed a strain specific pattern of 

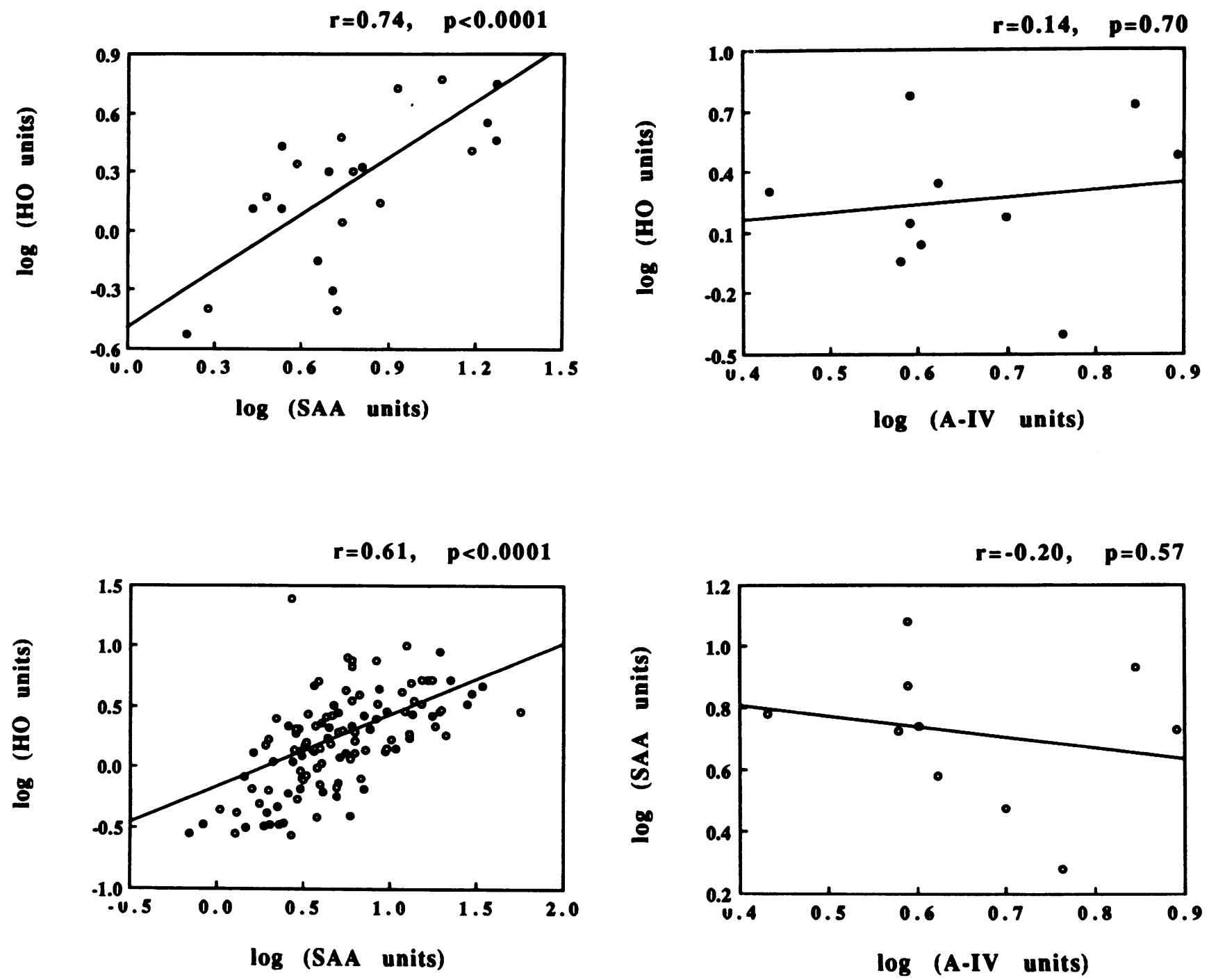

Figure 2. Cosegregation of inflammatory SAA (SAA) and heme oxygenase $(H O)$ in BXH recombinant inbred strains. Mice were maintained on the atherogenic diet for $5 \mathrm{wk}$ and $15 \mathrm{wk}$ before killing. Their liver RNA was extracted and the expression levels of inflammatory SAA and heme oxygenase were determined by dot blot assays. In the upper panel the averaged value of each strain was used, and in the lower panel the data of individual animals were used. The circles and dots represent the mice on the atherogenic diet for 5 and $15 \mathrm{wk}$, respectively. 3-9 mice were used for each strain.

levels of hepatic conjugated dienes associated with total lipids among the BXH RI strains (Table I). The levels of conjugated dienes were correlated among the strains with the induction of heme oxygenase mRNA $(r=0.69, P=0.01)$, SAA mRNA $(r=0.65, P=0.02)$ and NF-kB-like activity $(r=0.64, P$ $=0.03$ ) (Fig. 6). No correlation was observed with the levels of apo A-IV mRNA ( $r=0.04, P=0.89$ ) (Fig. 6). As observed with the parental strains, no significant correlations were observed between total lipid accumulation and liver gene induction (data not shown).

Cosegregation of aortic fatty streak formation with activation of hepatic genes and NF-kB-like factors. We originally examined susceptibility of BXH RI strains for aortic fatty streak formation using a semiquantitative lesion scoring technique

Figure 3. Absence of segregation of apo A-IV with inflammatory SAA $(S A A)$ and heme oxygenase $(H O)$ in $\mathrm{BXH}$ recombinant inbred strains. Mice were killed after having been maintained on the atherogenic diet for $15 \mathrm{wk}$. The hepatic mRNA levels of inflammatory SAA, heme oxygenase and apo A-IV were determined by using dot blot assays. 39 mice were included for each strain.

(23). The results suggested that the lesion development was determined by a major gene which was designated Ath-1 (for Atherosclerosis-1). We have now reexamined the BXH RI strains for lesion susceptibility with a more quantitative histological procedure developed by Paigen and co-workers (35), in which total lesion volume is estimated by quantitating lesion areas in serial sections of the proximal aorta $(35,36)$. Fig. 7 demonstrates that aortic lesion scores were highly concordant among the BXH RI and the parental strains with the levels of inflammatory SAA mRNA ( $r=0.79, P=0.002)$, heme oxygenase mRNA $(r=0.66, P=0.02)$, and activated NF-kBlike transcription factors $(r=0.84, P=0.0006)$. Aortic lesion development exhibited no correlation with levels of hepatic apo A-IV mRNA $(r=-0.14, P=0.70)$. Although the levels of hepatic conjugated dienes were correlated with hepatic gene induction, they did not exhibit significant cosegregation with aortic fatty streak formation $(r=0.37, P=0.23$ ). 


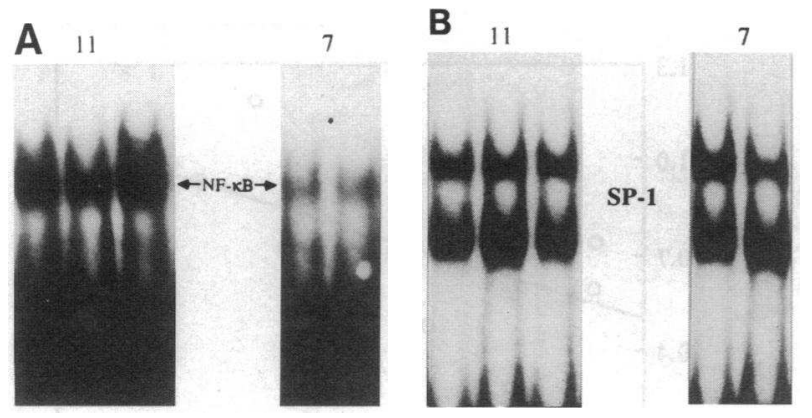

Figure 4. (A) Mobility shift assays for activated NF-kB-like transcription factors in liver nuclear extracts. Liver nuclear extracts obtained from the parental C57BL/6J and $\mathrm{C} 3 \mathrm{H} / \mathrm{HeJ}$ mice, as well as the $\mathrm{BXH}$ recombinant inbred strains, maintained on the atherogenic diet for 15 wk, were assayed for the activation of NF-kB-like transcription factors. The level of NF-kB in each liver sample was normalized to that for the constitutive transcription factor SP-1 in the same sample and also to NF-kB levels in an extract prepared from LPS-stimulated HeLa cells. Representative results from BXH 7 (7) and BXH 11 (11) are shown as examples. $(B)$ Mobility shift assays for the transcription factor SP1 in the mouse liver nuclear extracts. Shown are SP-1 mobility shifts in the same BXH 7 (7) and BXH 11 (11) samples as in $A$.

The fraction of variance of one trait that can be explained by a second trait is approximated by $r^{2}$. Therefore, $\sim 70 \%$ of the variance of aortic lesion formation (see Fig. 7), and $\sim 50$ and $60 \%$ of the variance of hepatic heme oxygenase and inflammatory SAA expression (see Fig. 5) are explained by the levels of the activated NF-kB-like transcription factors. Our results suggest that common genetic factors related to the activation of NF-kB-like transcription factors contribute significantly to both induction of hepatic inflammatory genes and development of aortic atherosclerotic lesions.

\section{Discussion}

The finding that genetic variations influencing inflammatory gene induction in response to an atherogenic diet cosegregate with the susceptibility to aortic fatty streak formation indicates that these processes are either directly related or that they share a common pathway. The results provide new and independent evidence for the "lipoprotein oxidation hypothesis" for atherosclerosis (1). In a previous report we showed that injection of MM-LDL into mice resulted in induction of the same set of genes as feeding the atherogenic diet $(20,21,42,43)$. These genes included M-CSF, JE, heme oxygenase, inflammatory $\mathrm{SAA}$, tissue factor and $\mathrm{KC} /$ gro. Since conjugated dienes accumulate in tissues of animals maintained on the atherogenic diet, it is likely that oxidized species of lipids, similar to those present in oxidized LDL, are responsible for the inflammatory response and atherogenesis. Moreover, the levels of conjugated dienes which accumulated on the atherogenic diet were correlated with inflammatory gene activation.

The identities of the genetic factors differing between strains C57BL/6J and C3H/HeJ are unknown, but our results suggest that they influence either lipid oxidation or cellular response to oxidized lipids. Such genetic factors, influencing local reactions to lipid peroxidation, are novel, but they could play an important role in the genetic susceptibility to heart disease in human populations. Lipid oxidation could be affected by genetic variations
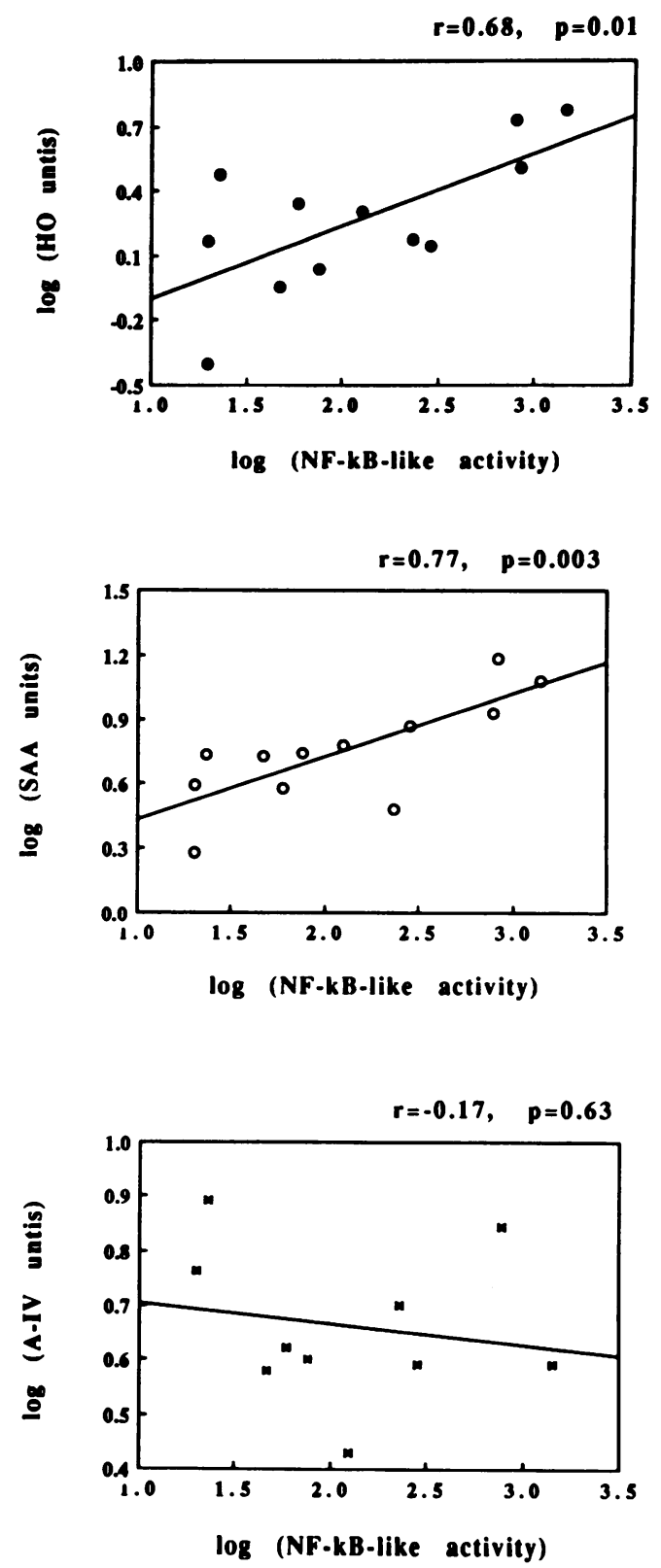

Figure 5. Cosegregation of liver inflammatory SAA (SAA) and heme oxygenase $(H O)$ with activated NF-kB-like transcription factors. After 15 wk of consumption of the atherogenic diet, the parental C57BL/6J and $\mathrm{C} 3 \mathrm{H} / \mathrm{HeJ}$ strains and $\mathrm{BXH}$ recombinant inbred strains were assessed for hepatic inflammatory SAA, heme oxygenase and apo A-IV mRNA levels by using dot blot assays. The activated NF-kB-like transcription factors were detected in liver nuclear extracts by using gel mobility shift assays. 3-9 mice were used in each group.

in genes involved in the production (e.g., lipoxygenase) or reduction (e.g., heme oxygenase, superoxide dismutase, Bcl-2 and the enzymes of the glutathione system) of lipid peroxides or reactive oxygen intermediates. Recent in vitro studies suggest that HDL may inhibit LDL oxidation. It is noteworthy that acute-phase HDL, which is enriched with the inflammatory SAA was deficient in the ability to inhibit LDL oxidation (44). Thus, the induction of inflammatory SAA by the atherogenic diet could potentially influence LDL oxidation in the arterial 

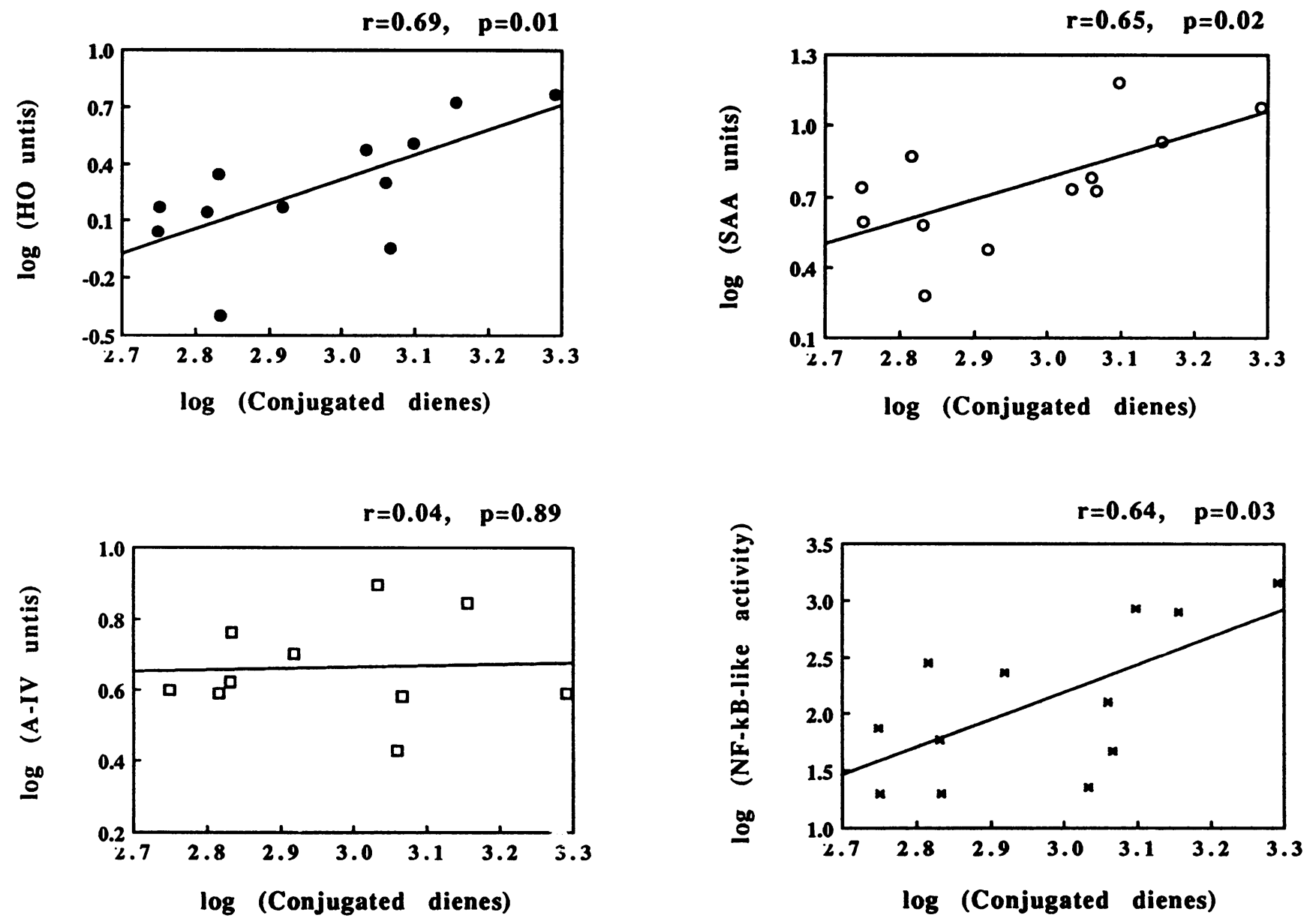

Figure 6. Cosegregation of hepatic lipid peroxide accumulation with inflammatory gene induction and NF-kB-like factor activation. Parental and BXH RI strains were fed an atherogenic diet for $15 \mathrm{wk}$, total hepatic lipids were extracted, and conjugated diene levels were measured spectrophotometrically (21). Three animals per group were studied. Inflammatory gene mRNA levels, apo A-IV levels, and activated NF-kB-like transcription factor levels (Table I) are plotted as function of conjugated diene levels.

wall. Transcriptional control of cellular responses to oxidative stress has been reported for the regulation of transcription factor USF through a shift in the redox state of the two cysteines in the helix-loop-helix region of the protein (45).

The observation that the levels of lipid peroxidation products, as estimated by levels of conjugated dienes, were correlated with inflammatory gene activation suggests that genetic factors controlling lipid oxidation are the primary determinants of genetic predisposition to atherosclerosis in this model. The identities of the oxidized lipid species that are responsible for inflammatory gene activation are unknown, and total levels of conjugated dienes probably represent a relatively crude estimate of the levels of the biologically active species. This may account for the failure to observe a significant correlation between conjugated diene levels and aortic fatty streak development.

$\mathrm{C} 3 \mathrm{H} / \mathrm{HeJ}$ mice are resistant to many of the effects of bacterial lipopolysaccharide (LPS). This resistance is due to mutation of a single gene, Lps, located on chromosome 4 (46). Since LPS induces many of the same genes as oxidized lipoproteins, we have considered the possibility that the Lps gene may be the major determining gene for the relative resistance of $\mathrm{C} 3 \mathrm{H} /$ $\mathrm{HeJ}$ mice to inflammatory mediator induction and fatty streak formation when challenged with the atherogenic diet. The re- sults of the present study demonstrate that the segregation of the Lps gene is discordant with the segregation of the other traits examined, indicating that the Lps gene is not a major determining factor (Table I). For example, strain BXH-8 was highly susceptible to lesion development and inflammatory mediator induction, but carries the Lps-resistant allele (from $\mathrm{C} 3 \mathrm{H} /$ $\mathrm{HeJ}$ ), whereas strain $\mathrm{BXH}-10$ was relatively resistant to the lesion development and inflammatory mediator activation but carries the Lps-sensitive allele (from C57BL/6J) (Table I). These results are consistent with our previous findings that the pathway for activation of inflammatory mediators by MM-LDL is distinct from that by LPS (20).

Our study supports a role for members of the NF-kB family of transcription factors in the pathway leading from oxidized lipids to inflammatory gene induction. These transcription factors exist as cytosolic dimers bound to an inhibitory molecule, IkB, and their activation results in the dissociation of IkB and translocation of the active subunits to the nucleus where their interaction with regulatory elements occurs (34). Our results are consistent with previous tissue culture studies indicating that MM-LDL can induce transcription in the absence of protein synthesis (47). They are also consistent with recent studies suggesting that the 

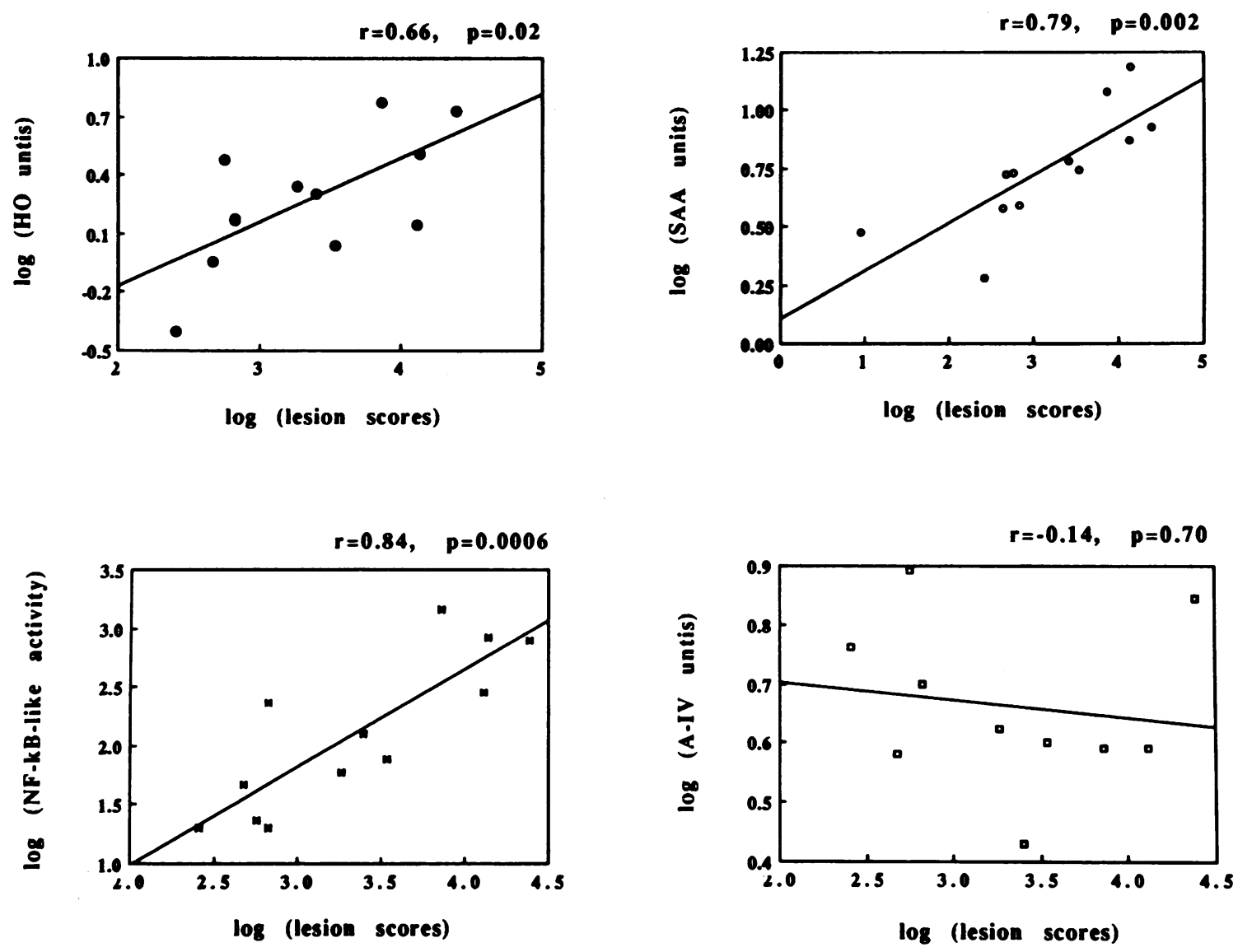

Figure 7. Cosegregation of liver inflammatory SAA $(S A A)$, heme oxygenase $(H O)$, and activated NF-kB-like factors with aortic atherosclerotic lesions. After 15 wk of consumption of the atherogenic diet, the parental C57BL/6J and C3H/HeJ strains and BXH recombinant inbred strains were assessed for aortic lesion formation by standard histological examination, for hepatic inflammatory SAA, heme oxygenase and apo A-IV mRNA levels by dot blot assays, and for liver active NF-kB-like transcription factors by mobility shift assays. 3-9 mice were used in each group.

activation of gene expression by MM-LDL is mediated by the cyclic AMP pathway (48), since this pathway has been associated with NF-kB activation (49).

We previously examined the segregation pattern of aortic lesion formation in two sets of RI strains, including the BXH set (23). The results suggested that aortic lesion development was determined by a major genetic factor, designated Ath-1, which was tentatively assigned to mouse chromosome 1 . Our present findings suggest that Ath-1 is identical to a major genetic factor determining inflammatory and oxidative stress responsive gene induction as well as NF-kB family activation in response to the atherogenic diet among the BXH set of RI strains. The identification of these biochemical markers for atherogenesis should facilitate the identification of the Ath-1 gene by a positional cloning strategy.

\section{Acknowledgments}

We wish to thank Dr. Pei-Zhen Xie for her help in scoring the aortic fatty streak lesions, Dr. Boris Ivandic for his help with measurement of hepatic conjugated dienes, and Pha Le for his assistance in RNA analysis.

This work was supported by US Public Health Service grant HL30568, the Laubisch Fund, the Cigarette and the Tobacco-Surtax Fund of the State of California through the Tobacco-Related Disease Research Program at the University of California.

\section{References}

1. Witztum, J. L., and D. Steinberg. 1991. Role of oxidized low density lipoprotein in atherogenesis. J. Clin. Invest. 88:1785-1792.

2. Parthasarathy, S., and J. L. Witztum. 1992. The role of oxidized low-density lipoproteins in the pathogenesis of atherosclerosis. Annu. Rev. Med. 43:219-225.

3. Haberland, M. E., and U. P. Steinbrecher. 1992. Modified low density lipoproteins: Diversity and biologic relevance in atherosclerosis. In Molecular Genetics of Coronary Artery Diseases A. J. Lusis, J. I. Rotter, and R. S. Sparkes, editors. 35-61.

4. Haberland, M. E., D. Fong, and L. Cheng. 1988. Malondialdehyde-altered protein occurs in atheroma of Watanabe heritable hyperlipidemic rabbits. Science (Wash. DC). 241:215-218.

5. Yla-Herttuala, S., W. Palinski, M. E. Rosenfeld, S. Parthasarathy, T. E. Carew, S. Butler, J. L. Witztum, and D. Steinberg. 1989. Evidence for the presence of oxidatively modified low density lipoprotein in atherosclerotic lesions of rabbit and man. J. Clin. Invest. 84:1086-1095.

6. Palinski, W., M. E. Rosenfeld, S. Yla-Herttuala, G. C. Gurtner, S. S. Socher, S. W. Butler, S. Parthasarathy, T. E. Carew, D. Steinberg, and J. L. Witztum. 1989. Low density lipoprotein undergoes oxidative modification in vivo. Proc. Natl. Acad. Sci. USA. 86:1372-1380.

7. Avogaro, P., G. B. Bon, and G. Cazzolato. 1988. Presence of a modified low density lipoprotein in human. Arteriosclerosis. 8:79-87.

8. Carew, T. E., D. C. Schwencke, and D. Steinberg. 1987. Anti-atherogenic effect of probucol unrelated to its hypercholeterolemic effect: evidence that antioxidants in vivo can selectively inhibit low density lipoprotein degradation in macrophage-rich fatty streaks and slow the progression of atherosclerosis in the Watanabe heritable hyperlipidemic rabbit. Proc. Natl. Acad. Sci. USA. 84:7725-7729.

9. Ferns, G. A. A., L. Forster, A. Stewart-Lee, M. Konneh, J. Nourooz-Zadeh, and E. E. Anggard. 1992. Probucol inhibits neointimal thickening and macrophage accumulation after balloon injury in the cholesterol-fed rabbit. Proc. Natl. Acad. Sci. USA. 89:11312-11316. 
10. Mao, S. J. T., M. T. Yates, R. A. Parker, E. M. Chi, and R. L. Jackson. 1991. Attenuation of atherosclerosis in a modified strain of hypercholesterolemic Watanabe rabbits with use of a probucol analogue (MDA 29,311) that does not lower serum cholesterol. Arterioscler. Thromb. 11:1266-1275.

11. Sparrow, C. P., T. W. Doebber, J. Olszewski, M. S. Wu, J. Ventre, K. A. Stevens, and Y-S. Chao. 1992. Low density lipoprotein is protected from oxidation and the progression of atherosclerosis is slowed in cholesterol fed rabbits by the antioxidant $N, N^{\prime}$-diphenyl-phenylenediamine. J. Clin. Invest. 89:1885-1891

12. Berliner, J. A., M. C. Territo, A. Sevanian, S. Ramin, J. A. Kim, B. Bamshad, M. Esterson, and A. M. Fogelman. 1990. Minimally modified low density lipoprotein stimulates monocyte endothelial cell interaction. J. Clin. Invest. 85:1260-1266.

13. Rajavashisth, T. B., A. Andalibi, M. C. Territo, J. A. Berliner, M. Navab, A. M. Fogelman, and A. J. Lusis. 1990. Induction of endothelial cell expression of granulocyte and macrophage colony-stimulating factors by modified low density low density lipoproteins. Nature (Lond.). 344:254-257.

14. Cushing, S. D., J. A. Berliner, A. J. Vanlente, M. C. Territo, M. Navab, F. Parhami, R. Gerrity, C. J. Schwartz, and A. M. Fogelman. 1990. Minimally modified low density lipoprotein induces monocyte chemotactic protein-1 in human endothelial cells and smooth muscle cells. Proc. Natl. Acad. Sci. USA 87:5134-5138.

15. Navab, M., S. S. Imes, S. Y. Hama, G. P. Hough, L. A. Ross, R. W. Bork, A. J. Valente, J. A. Berliner, D. C. Drinkwater, H. Laks, and A. M. Fogelman 1991. Monocyte transmigration induced by modification of low density lipoprotein in coculture of human aortic wall cells is due to induction of monocyte chemotactic protein 1 and is abolished by high density lipoprotein. J. Clin. Invest. 88:20392046.

16. Berliner, J. A., M. Territo, A. Andalibi, M. Navab, F. Liao, S. Cushing, S. Imes, J. Kim, B. Van Lenten, A. J. Lusis, and A. M. Fogelman. 1992. Modified lipoproteins and Atherogenesis. In Cellular and Molecular Biology of Atherosclerosis. J. A. M. Gotto. Springer-Verlag London Limited. 77-80.

17. Clinton, S. K., R. Underwood, L. Hayes, M. L. Sherman, D. W. Kufe and P. Libby. 1992. Macrophage colony-stimulating factor gene expression in vascular cells and in experimental and human atherosclerosis. Am. J. Pathol. 140:301-316.

18. Rosenfeld, M. E., S. Yla-Herttuala, B. A. Lipton, V. A. Ord, J. L. Witztum, and D. Steinberg. 1992. Macrophage colony-stimulating factor mRNA and protein in atherosclerotic lesion of rabbits and humans. Am. J. Pathol. 140:291-300.

19. Yla-Harttuala, S., B. A. Lipton, M. E. Rosenfeld, T. Sarkioja, T. Yoshimura, E. J. Leonard, J. L. Witztum, and D. Steinberg. 1991. Expression of monocyte chemoattractant protein 1 in macrophage-rich areas of human and rabbit atherosclerotic lesions. Proc. Natl. Acad. Sci. USA. 88:5252-5256.

20. Liao, F., J. A. Berliner, M. Mehrabian, M. Navab, L. L. Demer, A. J. Lusis, and A. M. Fogelman. 1991. Minimally modified low density lipoprotein is biologically active in vivo in mice. J. Clin. Invest. 87:2253-2257.

21. Liao, F., A. Andalibi, F. C. deBeer, A. M. Fogelman, and A. J. Lusis 1993. Genetic control of inflammatory gene induction and NF-kB-like transcription factor activation in response to an atherogenic diet in mice. J. Clin. Invest. 91:2572-2579.

22. Schreck, R., P. Rieber, and P. A. Baeuerle. 1991. Reactive oxygen intermediates as apparently widely used messengers in the activation of the NF-kB transcription factor and HIV-1. EMBO (Eur. Mol. Biol. Organ.) J. 10:22472258.

23. Paigen, B., D. Mitchell, K. Reue, A. Morrow, A. L. Lusis, and R. C LeBoeuf. 1987. Ath-1, a gene determining atherosclerosis susceptibility and high density lipoprotein levels in mice. Proc. Natl. Acad. Sci. USA. 84:3763-3767.

24. Lusis, A. J. 1993. The mouse model for atherosclerosis. Trends. Cardio vasc. Med. 3:135-143.

25. Paigen, B., A. Morrow, C. Brandon, D. Mitchell, and P. Holmes. 1985. Variation in susceptibility to atherosclerosis among inbred strains of mice. Atherosclerosis. 57:65-73.

26. Paigen, B., B. Y. Ishida, J. Verstuyft, R. B. Winters, and D. Albee 1990. Atherosclerosis susceptibility differences among progenitors of recombinant inbred strains of mice. Atherosclerosis. 110:316-323.

27. Chomczynski, P., and N. Sacchi. 1987. Single-step method of RNA isolation by acid guanidinium thiocyanate-phenol-chloroform extraction. Anal. Bio chem. 162:156-159.
28. Oberbämer, I. 1992. Retroposons do jump: a B2 element recently integrated in an 18S rDNA gene. Nucleic Acids Res. 20:671-677.

29. Kageyama, H., T. Hiwasa, K. Tokunaga, and S. Sakiyama. 1988. Isolation and characterization of a complementary DNA clone for a Mr 32,000 protein which is induced with tumor promoters in BALB/c 3T3 cells. Cancer Res. 48:4795-4798.

30. Morrow, J. C., R. S. Stearman, C. G. Peltzman, and D. A. Potter. 1981 Induction of hepatic synthesis of serum amyloid A protein and actin. Proc. Natl. Acad. Sci. USA. 78:4718-4722.

31. Stearman, R. S., C. A. Lowell, C. G. Peltzman, and J. F. Morrow. 1986 The sequence and structure of a new serum amyloid A gene. Nucleic Acids Res. 14:797-809.

32. Dignam, J. D., R. M. Lebovitz, and R. G. Roeder. 1983. Accurate transcription initiation by RNA polymerase II in a soluble extract from isolated mammalian nuclei. Nucleic Acids Res. 11:1475-1498.

33. Osborn, L., S. Kunkel, and G. J. Nabel. 1989. Tumor necrosis factor a and interleukin 1 stimulate the human immunodeficiency virus enhancer by activation of the nuclear factor kB. Proc. Natl. Acad. Sci. USA. 86:2336-2340.

34. Baeuerle, P. A. 1991. The inducible transcription activator NF-kB: regulation by distinct protein subunits. Biochim. Biophys. Acta. 1072:63-80.

35. Paigen, B., A. C. Morrow, P. A. Holmes, D. Mitchell, and R. A. Williams. 1987. Quantitative assessment of atherosclerotic lesions in mice. Atherosclerosis. 68:231-240.

36. Qiao, J-H., C. L. Welch, P-Z. Xie, M. C. Fishbein, and A. J. Lusis. 1993 Involvement of the tyrosinase gene in the deposition of cardiac lipofuscin in mice. J. Clin. Invest. 92:2: '5-2393.

37. Williams, S. L S. G. Grant, K. Reue, B. Carrasquillo, A. J. Lusis, and A. J. Kinniburgh. 198 . cis-acting determinants of basal and lipid-regulated apolipoprotein A-IV expression in mice. J. Biol. Chem. 264(32):19009-19016.

38. Visvanathan, K. V., and S. Goodbourn. 1989. Double-stranded RNA activates binding of NF-kB to an inducible element in the human b-interferon promotor. EMBO (Eur. Mol. Biol. Organ.) J. 8:1129-1138.

39. Rajavashisth, T. B., K. Doan, and J. Mehta. 1993. NF-kB binding cisDNA elements mediate transcription activation of M-CSF gene by minimally modified LDL. FASEB (Fed. Am. Soc. Exp. Biol.) J. 7:A341. (Abstr.)

40. Li, X., and W. S.-L. Liao. 1991. Expression of rat serum amyloid A1 gene involves both $\mathrm{C} / \mathrm{EBP}$-like and NF-kB-like transcription factors. J. Biol. Chem. 23:15192-15201.

41. Mackman, N., K. Brand, and T. S. Edgington. 1991. Lipopolysaccharidemediated transcriptional activation of the human tissue factor gene in THP-1 monocytic cells required both activator protein 1 and nuclear factor $\mathrm{kB}$ binding site. J. Exp. Med. 174:1517-1526.

42. Fei, H., F. Liao, and T. A. Drake. 1993. Regulation of tissue factor gene expression by minimally oxidized low density lipoprotein. Thromb. Haemostasis. 69:1202. (Abstr.)

43. Fei, H., F. Liao, and T. A. Drake. 1993. Genetically regulated tissue factor gene induction in mice fed an atherogenic diet. FASEB (Fed. Am. Soc. Exp. Biol.) J. 7:A491. (Abstr.)

44. Hama, S. Y., M. Navab, F. C. deBeer, and A. M. Fogelman. 1992. Acutephase high density lipoprotein does not prevent but amplifies the modification of low density lipoprotein. Circulation. 86:I-423. (Abstr.)

45. Pognonec, P., H. Kato, and R. Roeder. 1992. The helix-loop-helix/leucine repeat transcription factor USF can be functionally regulated in a redox-dependen manner. J. Biol. Chem. 267(34):24563-24567.

46. Watson, J., K. Kelly, M. Largen, and B. A. Taylor. 1978. The genetic mapping of a defective LPS response gene in $\mathrm{C} 3 \mathrm{H} / \mathrm{HeJ}$ mice. J. Immunol. 120:422-424.

47. Bork, R. W., K. L. Svenson, M. Mehrabian, A. J. Lusis, A. M. Fogelman, and P. A. Edwards. 1992. Mechanism controlling competence gene expression in murine fibroblasts stimulated with minimally modified LDL. Arterioscler. Thromb. 12:800-806.

48. Parhami, F., Z. T. Fang, A. M. Fogelman, A. Andalibi, M. C. Territo and J. A. Berliner. 1993. Minimally modified low density lipoprotein-induced inflammatory response in endothelial cells are mediated by cyclic.adenosine monophoshpate. J. Clin. Invest. 92:471-478.

49. Shirikawa, F., and S. B. Mizel. 1989. In vitro activation and nuclear translocation of NF-kappa B catalyzed by cyclic AMP-dependent protein kinase and protein kinase C. Mol. Cell. Biol. 9:2424-2430. 